Elton Tizziani

\title{
O Efeito Disposição na Indústria Brasileira de Fundos de Investimento em Ações: Um Estudo Em Finanças Comportamentais
}

Dissertação apresentada como requisito parcial para obtenção do grau de Mestre pelo Programa de PósGraduação em Administração de Empresas da PUC-Rio.

Orientador: Prof. Marcelo Cabús Klötzle 


\section{Pontifícia Universidade Católica $_{\text {a }}$

Elton Tizziani

O Efeito Disposição na Indústria Brasileira de Fundos de Investimento em Ações: Um Estudo em Finanças Comportamentais

Dissertação apresentada como requisito parcial para obtenção do grau de Mestre pelo Programa de PósGraduação em Administração de Empresas da PUC-Rio. Aprovada pela Comissão Examinadora abaixo assinada.

Prof. Marcelo Cabús Klötzle Orientador Departamento de Administração - PUC-Rio

Prof. Walter Lee Ness Departamento de Administração - PUC-Rio

Prof. Kátia Rocha IPEA

Prof. Nizar Messari

Vice-Decano de Pós-Graduação do CCS

Rio de Janeiro, 14 de agosto de 2008. 
Todos os direitos reservados. É proibida a reprodução total ou parcial do trabalho sem autorização da universidade, do autor e do orientador.

\section{Elton Tizziani}

Graduou-se em Administração de Empresas na Universidade Federal do Rio de Janeiro (UFRJ) em 2003. Atuou como auditor na Ernst \& Young e como Controller em empresa do segmento de eletrônicos. Atualmente é inspetor da Comissão de Valores Mobiliários.

Ficha Catalográfica

Tizziani, Elton

O efeito disposição na Indústria Brasileira de Fundos de Investimento em Ações: Um estudo em Finanças Comportamentais / Elton Tizziani ; orientador: Marcelo Cabús Klötzle. - 2008.

78 f. : il. ; $30 \mathrm{~cm}$

Dissertação (Mestrado em Administração) - Pontifícia Universidade Católica do Rio de Janeiro, Rio de Janeiro, 2008.

Inclui bibliografia

1. Administração - Teses. 2. Finanças comportamentais. 3. Teoria do prospecto. 4. Efeito disposição. 5. Fundos de Investimento em ações. I. Klötzle, Marcelo Cabús. II. Pontifícia Universidade Católica do Rio de Janeiro. Departamento de Administração. III. Título.

CDD:658 
À minha família, por ser a minha fonte de inspiração na vida pessoal, profissional e acadêmica. 


\section{Agradecimentos}

Gostaria de agradecer ao meu orientador Prof. Dr. Marcelo Cabús Klötzle pela paciência, já que o resultado demorou mais que o esperado, apoio no desenvolvimento do trabalho e compreensão do momento que eu atravessava em minha vida profissional.

Agradeço a grande contribuição prestada por todo corpo docente durante os 18 meses em que passaram parte de seus conhecimentos, sobretudo pelo Prof. Dr. Luís Felipe Motta com a cadeira de Avaliação de Projetos, pelo Prof. Dr. Walter Lee Ness com seu curso “Administração de Carteiras”, pelo Prof. Dr. Luis Eduardo Brandão com o curso de Opções Reais e pelo Prof. Dr. Antônio Carlos Figueiredo com o curso de Derivativos.

Ao meu irmão Emerson, que forneceu apoio imprescindível na organização e manipulação dos mais de 1.000 .000 de registros obtidos junto à Comissão de Valores Mobiliários para elaboração do teste empírico realizado no presente estudo.

Também gostaria de registrar meu agradecimento aos funcionários da secretaria acadêmica Sra. Teresa Campos e Sr. Fábio Etienne, que sempre foram amigáveis, disponíveis e forneceram informações fundamentais que me ajudaram ao longo de todo o período do curso de mestrado. 


\section{Resumo}

Tizziani, Elton; Klötzle, Marcelo Cabús. O Efeito Disposição na Indústria Brasileira de Fundos de Investimento em Ações: Um Estudo em Finanças Comportamentais. Rio de Janeiro, 2008. 78p. Dissertação de Mestrado Departamento de Administração, Pontifícia Universidade Católica do Rio de Janeiro.

Esta dissertação tem como objetivo testar o efeito disposição, que é a tendência dos investidores em vender os investimentos ganhadores mais rapidamente que os investimentos perdedores, através da análise das carteiras de todos os Fundos Brasileiros de Investimentos em Ações, no período compreendido entre novembro de 2003 e março de 2008. Embora a análise do número de transações revele que os fundos de investimento estão sujeitos ao efeito disposição, diferentemente do mercado acionário americano, quando são analisados os volumes transacionados, não é possível identificar o efeito disposição, especialmente em relação aos fundos de varejo, os que apresentaram a maior tendência de realização de perdas em detrimento dos ganhos.

\section{Palavras Chave:}

Finanças Comportamentais; Teoria do Prospecto; Efeito Disposição; Fundos de Investimento em Ações. 


\section{Abstract}

Tizziani, Elton; Klötzle, Marcelo Cabús (Advisor). The Disposition Effect in the Brazilian Market of Equity Funds: A Survey in Behavioral Finance. Rio de Janeiro, 2008. 78p. MSc. Dissertation - Departamento de Administração, Pontifícia Universidade Católica do Rio de Janeiro.

The goal of this study is to test the disposition effect, the tendency of investors to sell winning investments too soon and hold losing investments too long, by analyzing all the Brazilian Equity Funds portfolios from november 2003 to march 2008. Although the analysis based on the number of trades shows the Equity Funds are subject to the disposition effect, unlike the American stock market, when the analysis is based on the trading volume, the disposition effect is not identified, mainly in the funds open to non-qualified investors, that showed the stronger tendency to realize the loses instead the gains.

\section{Key words:}

Behavioral Finance; Prospect Theory; Disposition Effect; Equity Funds. 


\section{Sumário}

1 Introdução 13

2 Referencial Teórico 16

2.1. Finanças Modernas 16

2.2. Finanças Comportamentais 17

2.3. Teoria do Prospecto 19

2.4. Efeito Disposição 23

3 Fundos de Investimento 31

3.1. A Indústria Brasileira de Fundos de Investimento 31

3.2. Fundos de Investimento 32

3.3. A Evolução da Regulamentação 33

3.4. Panorama Atual e Tamanho da Indústria 37

3.5. Quantidade de Fundos 39

3.6. Patrimônio dos Fundos 40

3.7. Número de Cotistas 42

3.8. Concentração da Indústria 43

3.9. Fundos de Investimentos em Ações 44

4 Metodologia 46

4.1. Coleta de Dados 46

$\begin{array}{ll}\text { 4.2. Teste Empírico } & 47\end{array}$

5 Resultados $\quad 55$

6 Conclusões 63

6.1. Discussões e Recomendações 64

$\begin{array}{ll}7 \text { Referências Bibliográficas } & 67\end{array}$

ANEXO I - Carteiras Teóricas do IBrX-50 69 
ANEXO II - Tabelas Mensais de Ganhos e Perdas

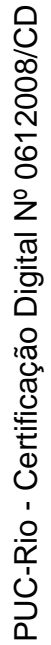




\section{Lista de figuras}

Figura 1: Função de valor da teoria do prospecto. 20

Figura 2: Propensão ao risco na região de perdas. 22

Figura 3: Aversão ao risco na região de ganhos. 22

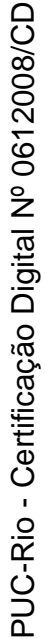




\section{Lista de tabelas}

Tabela 1: Volume Transacionado na Bolsa de Valores de São Paulo, segmentado por Tipo de Investidor, nos anos de 2006 e 2007.

Tabela 2: Quantidade de Fundos da Indústria Brasileira, segmentados por Classe, nos anos de 2006 e 2007.

Tabela 3: Patrimônio Líquido dos Fundos da Indústria Brasileira, segmentados por Classe, nos anos de 2006 e 2007.

Tabela 4: Patrimônio Líquido dos Fundos da Indústria Brasileira, segmentados por Classe e Categoria, no ano de 2007.

Tabela 5: Número de Cotistas dos Fundos da Indústria Brasileira, segmentados por Classe, nos anos de 2006 e 2007.

Tabela 6: Concentração da Indústria Brasileira de Fundos, segmentados por Administrador, no ano de 2006.

Tabela 7: Teste estatístico do efeito disposição por transação (valores agregados).

Tabela 8: Teste estatístico do efeito disposição por volume (valores agregados).

Tabela 9: Teste estatístico do efeito disposição por transação nos fundos para investidores qualificados.

Tabela 10: Teste estatístico do efeito disposição por transação nos fundos de varejo.

Tabela 11: Teste estatístico do efeito disposição por volume nos fundos para investidores qualificados.

Tabela 12: Teste estatístico do efeito disposição por volume nos fundos de varejo.

Tabela 13: Percentual de transações realizadas pelos fundos para investidores qualificados, por faixa de resultado bruto obtido.

Tabela 14: Percentual de transações realizadas pelos fundos de varejo, por faixa de resultado bruto obtido.

Tabela 15: Percentual do volume de ganhos e perdas realizadas pelos fundos para investidores qualificados, por faixa de resultado bruto obtido.

Tabela 16: Percentual do volume de ganhos e perdas realizadas pelos fundos de varejo, por faixa de resultado bruto obtido. 


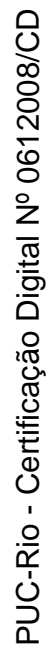

"Nunca diga às pessoas como fazer as coisas. Diga-lhes o que deve ser feito e elas surpreenderão você com sua engenhosidade."

George Patton. 